\title{
Measurement of Patient Satisfaction as a Quality Indicator of Hospital Health Services: The Case of Outpatient Clinics in General Hospital
}

\author{
Georgoudi Ekaterina ${ }^{1}$, Kyriazis Stavros ${ }^{1}$, Mihalache Anca ${ }^{2}$, Kourkouta Lambrini ${ }^{2}$, \\ ${ }^{1}$ General Hospital "Evangelismos" of Athens, Athens, Greece \\ ${ }^{2}$ Department of Nursing, Alexander Technological Educational Institute of Thessaloniki, Thessaloniki, Greece
}

Email address:

georgk1@otenet.gr (G. Ekaterina), lkourkouta@nurse.teithe.gr (K. Stavros), anka.mihalake@gmail.com (M. Anca), laku1964@yahoo.gr (K. Lambrini)

${ }^{*}$ Corresponding author

\section{To cite this article:}

Georgoudi Ekaterina, Kyriazis Stavros, Mihalache Anca, Kourkouta Lambrini. Measurement of Patient Satisfaction as a Quality Indicator of Hospital Health Services: The Case of Outpatient Clinics in General Hospital. Science Journal of Public Health.

Vol. 5, No. 2, 2017, pp. 128-135. doi: 10.11648/j.sjph.20170502.10

Received: January 8, 2017; Accepted: January 19, 2017; Published: February 23, 2017

\begin{abstract}
Purpose: The measurement of patient satisfaction by the provided health services in outpatient clinic of the General Hospital of Athens. Material-Method: To measure the satisfaction of health service users was chosen a sample of 400 people using the method of stratified random sampling. The data were collected using a weighted structured questionnaire in those who had an appointment with the hospital doctors (period from 1st to June 30th 2012). The evaluation of patient satisfaction for services imprinted in two ways: (a) assessment of total services in ten-point scale, where 1 represents dissatisfied and 10 very satisfied and (B) assessment of individual medical, nursing and administrative services with the five-point scale. The five-point scale was established as follows: value 1: very bad 2: rather bad 3: neither good nor bad, 4: rather good 5: very good. For the statistical analysis was used descriptive statistics, $\mathrm{t}$ test and ANONA test. Results: The response percentage of interviewees reached $83.25 \%$. In assessing the overall satisfaction was found that in the ten-point scale, the Hospital is evaluated positively. The average total score of evaluation is quite high (8.3). Important parameters of satisfaction for the majority of patients were courtesy, specialized knowledge and the professionalism of the staff of outpatient clinic. $85.29 \%$ of the sample declared absolutely satisfied by the behavior of the reception staff, $72.37 \%$ by the behavior of doctors, $69.67 \%$ by the quality of nursing care. However, the problematic aspects of the visit were identified to the responsiveness, the access, the outpatient clinics and the accommodations infrastructure. The lowest percentage of completely satisfied corresponds to the replies on the notice boards and on the information at the hospital entrance (5.41\% and 5.71\% respectively). Dissatisfaction was expressed for the long waiting time between the desired date for visit and the scheduled date (percentage of fully satisfied $14.71 \%$ ), as well as for waiting time in order to be respect the scheduled time (percentage of fully satisfied $12.01 \%$ ). Noteworthy is that the majority of interviewees would recommend the hospital to friends and family environment (percentages: definitely yes $58,86 \%$, rather yes $36.94 \%$ ). Conclusions: The overall assessment of the services provided by the outpatient clinic of Hospital was positive. However, it appeared to have problems in the organization, delays and infrastructure of clinics, for which must be taken corrective measures to ensure that the services that patients benefit are characterized by high quality.
\end{abstract}

Keywords: Public Hospitals, Outpatient Clinics, Patient Satisfaction

\section{Introduction}

The researches on satisfaction of patients constitute in the last 20 years the most common practices of extracting information for proper planning and organization of health services. In the past, all quality assessments were based exclusively in terms of the personnel and specialized experts. In the 90 's more attention was given to the patients' perception of the quality of health services, from researchers, institutions and policymakers experts of health [1]. Now all experts in the 
quality improvement of health services recognize patient satisfaction as an important indicator of quality of health services [2].

The patient satisfaction became also a determining factor and an efficiency marker for measuring the success of doctors and hospitals. In the United States doctors bonuses are linked with the assessment of their patients. In the United Kingdom were implemented conventions to the medical staff with which are provided bonus that can exceed to $30 \%$ of the basic pay of doctors, for achieving quality targets [3]. The scoring system gives rewards not only for performance on clinical quality efficacy indicators, but the conduct of patient satisfaction research promotes the active participation of citizens in the context of feedback for decision-making, aiming to improve the provided health care [4].

These developments highlight the fact that a greater patient satisfaction leads in many ways to benefits for health sector, as it is reflected in several studies [5]. Patient satisfaction is considered as a therapeutic intervention while its measurement can be successfully used in the personnel management, decision making, evaluation of organizational change and promoting health services after studying the market conditions [6], [7].

In the international literature is mentioned that $>95 \%$ of the units / health services somehow are investigating aspects of satisfaction of users regarding their services while there is an abundance of published studies in electronic databases [8], [9].

According to Donabedian, patients are a valuable and essential source of information for the evaluation of the health services effort [10], [11]. The concept of satisfaction is directly linked to the patient's previous experiences, the needs and the expectations, as well as to the care provided [12], [13]. Moreover is stated that patient satisfaction is subjective and relates to their cultural behavior [14], [15].

Furthermore, it appears that the most significant determinants of patient satisfaction from outpatient clinics services is the professionalism of the staff (doctors mostly) and the interpersonal relationships with patients. Is supported that the respect towards the individuality and the dignity of patients affects the degree of satisfactions [16], [17]. Very important role play also the communication between staff and patients, with main reference the information, the discussion of the problem and the education of the patient by the physician [18]. In addition, the doctor examination time, the training and the technical staff skills are also important parameters for user satisfaction [19]. As studies have shown, other factors that influence the degree of patient satisfaction are the processing time of the proceedings', waiting lists for the appointment day and time delays in appointments [20]. Lastly, according to related studies, the infrastructure and facilities of outpatient clinic also contribute in shaping the satisfaction level [19].

The purpose of this research was to assess the degree of patients satisfaction with the services provided by the outpatient clinic (medical, nursing, organizational and accommodation) of General Hospital «Evangelismos» of Athens.

\section{Material and Method}

The study material was a sample of 400 people who attended the outpatient clinic during the period 1st to 30th June 2012. The data were collected using a weighted structured questionnaire in those who had an appointment with the hospital doctors. The research was coordinated by the Directorate of Quality and Efficiency of Ministry of Health, to measure patient satisfaction from health services in outpatient clinics, but also in hospitalized patients from medical services in Hospital Departments. In the Hospital the research was coordinated by officers of the Office of Quality and the Citizen Support Office, in cooperation with the Directors and Heads of Hospital Services.

\section{Questionnaire Structure}

The questionnaire was anonymous and included 32 closed questions and one of open typeat the end (except those for the demographic characteristics). [Annex 1]

Specifically:

$1^{\text {st }}$ Section: Includes questions regarding the telephone service, the behavior of reception staff in the outpatient clinic, the waiting time until the meeting with the medical staff, the information, the marking sites, the existence of free seats, the temperature of space, quietness, the cleanliness of the operating and auxiliary spaces and accessibility to people with disabilities (Annex, Questionnaire 2 Questions 1-11).

$2^{\text {nd }}$ Section: Includes questions about the waiting time, the respecting of scheduled time, the waiting time for an examination and the results issuing time (Annex, Questionnaire 2 Questions 12-15).

$3^{\text {rd }}$ Section: Includes questions about behavior and respect for the personality from the medical staff of the hospital during the clinical and laboratory tests (Annex, Questionnaire 2 Questions 16-17).

$4^{\text {th }}$ Section: Includes questions about health care, the behavior, the psychological support and information from the medical staff (Annex, Questionnaire 2 Questions 18-22).

$5^{\text {th }}$ Section: Includes questions about health care, the behavior and the psychological support of the hospital nursing staff (Annex, Questionnaire 2 Questions 23-25).

$6^{\text {th }}$ Section: Includes questions about how the patient was treated during the hospitalization by the administrative staff of the hospital (Annex, Questionnaire 2 Questions 26-27).

$7^{\text {th }}$ Section: Includes questions about the way of dealing with the attendants or the patient's visitors, how to deal with examining procedure in order to protect the privacy and security of personal information (Privacy) (Annex, Questionnaire 2 questions 28-29).

$8^{\text {th }}$ Section: Includes general questions about the overall evaluation of the patient for the behavior of the hospital staff, the provided care, about whether to choose again the hospital and whether to recommend it to someone else (Annex, Questionnaire 2 Questions 30-32).

$9^{\text {th }}$ Section: Includes questions about personal, demographic and social data, such as citizenship, education 
level, gender and insurance organization (Annex - Preamble).

$10^{\text {th }}$ Section: Includes an open type question where the patient can note anything he wants on his experience during his stay in hospital (Annex, Questionnaire 2 Any observations or suggestions).

\subsection{Questionnaires Distribution}

The Questionnaires were distributed to patients who had completed their scheduled meeting with the doctor.

\subsection{Filling Questionnaires}

The questioner was filled either by the patients themselves or by the escorts of patients who: i) do not wish to fill in themselves, ii) were elderly and was difficult to fill in themselves, iii) had low educational level, fact which required the assistance of an attendant.

The participation in the research was anonymous and voluntary. The final sample consisted 400 patients of outpatient clinic who wanted to participate and where given them the corresponding questionnaires. The filling time of each questionnaire was an average of 20 minutes. The advantage of this method is that it is the least expensive and also allows complete anonymity, so the answers be free of any sense of fear and patient dependency, and therefore franker and more objective. At the same time, there is no inhibition on the answer, that there is no stress or non-satisfaction of the researcher who is absent. The method was preferred instead a personal interview, given the human resources that would be required in the second case. It also took into consideration the fact that based on previous years' data; the large number of incoming patients could help to achieve a satisfactory degree of interviewees' response by a sufficient sample size within a limited time frame.

It was attempted a stratification of the clinics of the General Hospital " Evangelismos" according to the number of visits made during the 2011 in each clinic. For the statistical analysis was used descriptive statistics, $t$ test and ANONA test.

\section{Results}

In total there were collected 333 questionnaires that included socio- demographic characteristics and questions about the degree of satisfaction. The turnout was $83.25 \%$. The filling of the questionnaire was in highest percentage made by the patients themselves $88.8 \%$ (294) and $6.01 \%$ (20) by the escorts of those patients who would not wish to complete it themselves or were too old, so it was difficult to complete it on their own. In a percentage of 5.71\% (19) did not answer the question to complete the questionnaire.

The demographic and social characteristics are presented in Table 1 . The majority of the sample were women $(60.06 \%)$. Almost entirely (96.4\%), the interviewees were insured and were Greek Citizenship. The largest percentage (58.26\%) of the sample was $>45$ years. The majority completed high school education $(41,44 \%)$, while a high percentage $(29.97 \%)$ were university graduates.

Table 1. Socio-demographic characteristics of the studied population.

\begin{tabular}{lll}
\hline CHARACTERISTICS & \% & N (333) \\
\hline Gender & 39 & 131 \\
Man & 60,06 & 200 \\
Woman & 0,6 & 2 \\
Did not answer & & \\
Age & 58,26 & 194 \\
$>45$ & 38,44 & 128 \\
$<45$ & 3,3 & 11 \\
Did not answer & & \\
Insurance & 96,4 & 321 \\
Yes & 1,8 & 6 \\
No & 1,8 & 6 \\
Did not answer & & \\
Nationality & 96,40 & 321 \\
Greek & 3,6 & 12 \\
Other & & \\
Education level & 27,7 & 90 \\
Until 3rd Gymnasium & 41,44 & 138 \\
High School & 29,97 & 97 \\
University or Technological Educational Institute & 2,4 & 8 \\
Did not answer & & \\
\hline
\end{tabular}

\subsection{Reception-Environment}

The satisfaction of the dimensions concerning the accommodation facilities and the environment (cleanliness, quiet, temperature, information signs) is at a relatively low percentage $(5.4 \%-45 \%)$. Percentage $(85.29 \%)$ stated absolutely satisfied with the behavior of the reception staff, but very small percentage $(5.7 \%)$ by the provided information on entering in hospital.

The $37.54 \%$ were absolutely satisfied with the telephone service concerning the appointment and the essential information related to the infirmary that was to visit and $44.74 \%$ by the waiting time for examination by the physician. At the question about accessibility for people with disabilities the satisfaction rates fluctuate from $16.52 \%$ to $33.63 \%$.

Table 2. Evaluation of section "Reception-Environment".

\begin{tabular}{|c|c|c|c|c|c|c|c|c|c|c|c|c|c|c|}
\hline \multirow[t]{2}{*}{ Reception - Environment } & \multicolumn{2}{|c|}{ Very good } & \multicolumn{2}{|c|}{ Rather good } & \multicolumn{2}{|c|}{$\begin{array}{l}\text { Neither good } \\
\text { nor bad }\end{array}$} & \multicolumn{2}{|c|}{ Rather bad } & \multicolumn{2}{|c|}{ Very bad } & \multicolumn{2}{|c|}{$\begin{array}{l}\text { Did not } \\
\text { answer }\end{array}$} & \multicolumn{2}{|c|}{ Total } \\
\hline & $\%$ & $\mathbf{N}$ & $\%$ & $\mathbf{N}$ & $\%$ & $\mathbf{N}$ & $\%$ & $\mathbf{N}$ & $\%$ & $\mathbf{N}$ & $\%$ & $\mathbf{N}$ & $\%$ & $\mathbf{N}$ \\
\hline Telephone service (appointment) & 37,54 & 125 & 34,53 & 115 & 17,12 & 57 & 4,8 & 16 & 0,30 & 1 & 5,71 & 19 & 100 & 333 \\
\hline The behavior of the staff who greeted you & 85,29 & 284 & 6,91 & 23 & 3,3 & 11 & 2,7 & 9 & 0 & 0 & 1.8 & 6 & 100 & 333 \\
\hline Waiting time until seeing a doctor & 44,74 & 149 & 27,33 & 91 & 17,42 & 58 & 3 & 10 & 1,8 & 6 & 5,71 & 19 & 100 & 333 \\
\hline Provision of information & 5,71 & 19 & 74,17 & 247 & 13,51 & 45 & 1,2 & 4 & 0.3 & 1 & 5,11 & 17 & 100 & 333 \\
\hline Information signs & 5,41 & 18 & 78,38 & 261 & 88,71 & 29 & 2,4 & 8 & 0,9 & 3 & 4,2 & 14 & 100 & 333 \\
\hline Free seats & 40,24 & 134 & 25,83 & 86 & 30,33 & 101 & 0,9 & 3 & 0,6 & 2 & 2,1 & 7 & 100 & 333 \\
\hline
\end{tabular}




\begin{tabular}{|c|c|c|c|c|c|c|c|c|c|c|c|}
\hline \multirow{2}{*}{$\begin{array}{l}\text { Reception - Environment } \\
\text { Spaces temperature (heating - cooling) }\end{array}$} & Very good & Rather good & $\begin{array}{l}\text { Neither good } \\
\text { nor bad }\end{array}$ & \multicolumn{2}{|c|}{ Rather bad } & \multicolumn{2}{|c|}{ Very bad } & \multicolumn{2}{|c|}{$\begin{array}{l}\text { Did not } \\
\text { answer }\end{array}$} & \multicolumn{2}{|c|}{ Total } \\
\hline & $45,65 \quad 152$ & $19,22 \quad 64$ & $29,73 \quad 99$ & 1,2 & 4 & 0 & 0 & 4,2 & 14 & 100 & 333 \\
\hline Silence & $21,62 \quad 72$ & $43,54 \quad 145$ & $27,93 \quad 93$ & 2 & 12 & 0,9 & 3 & 2,4 & 8 & 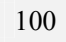 & 333 \\
\hline $\begin{array}{l}\text { Cleanliness of auxiliary areas (W. C., } \\
\text { bathrooms, etc.) }\end{array}$ & $19,82 \quad 66$ & $37,24 \quad 124$ & $31,83 \quad 106$ & 0,9 & 3 & 3,3 & 11 & 6,91 & 23 & 100 & 333 \\
\hline Accessibility for disabled persons & $16,52 \quad 55$ & $33,63 \quad 112$ & $12,91 \quad 43$ & 7,51 & 25 & 6,91 & 23 & 22,52 & 75 & 100 & 333 \\
\hline
\end{tabular}

\subsection{Servicesspeed}

The long waiting time between the desire to visit and the realization of the visit to outpatient clinic is evaluated as dissatisfaction causative agent. The $31.83 \%$ of patients expressed moderate satisfaction in rating for their impressions as neither good nor bad and $14.41 \%$ absolute dissatisfaction. Almost the same is about the percentage of fully satisfied (Table. 3) When asked about the respect for scheduled time, the largest proportion were satisfied (43.84\%) and $15.32 \%$ were completely dissatisfied. Dissatisfaction is expressed by the prolonged time spent in the waiting room. About waiting time for testing the impressions of interviewees were rather good for about half $(48.95 \%)$ and neither good nor bad in percentage $(28.23 \%)$. For the waiting time until the issue result of examinations, the satisfaction rates fluctuate from $19.82 \%$ to $36.94 \%$, while the rating neither good nor bad $32.43 \%$.

Table 3. Evaluation of section \$ervices speed."

\begin{tabular}{|c|c|c|c|c|c|c|c|c|c|c|c|c|c|c|}
\hline \multirow[t]{2}{*}{ SERVICES SPEED } & \multicolumn{2}{|c|}{ Very good } & \multicolumn{2}{|c|}{ Rather good } & \multicolumn{2}{|c|}{$\begin{array}{l}\text { Neither good } \\
\text { nor bad }\end{array}$} & \multicolumn{2}{|c|}{ Rather bad } & \multicolumn{2}{|c|}{ Very bad } & \multicolumn{2}{|c|}{$\begin{array}{l}\text { Did not } \\
\text { anwer }\end{array}$} & \multicolumn{2}{|c|}{ Total } \\
\hline & $\%$ & $\mathbf{N}$ & $\%$ & $\mathbf{N}$ & $\%$ & $\mathbf{N}$ & $\%$ & $\mathbf{N}$ & $\%$ & $\mathbf{N}$ & $\%$ & $\mathbf{N}$ & $\%$ & $\mathbf{N}$ \\
\hline Waiting time for an appointment & 14,71 & 49 & 27,33 & 91 & 31,83 & 106 & 5,41 & 18 & 14,41 & 48 & 6,21 & 21 & 100 & 333 \\
\hline Respect of scheduled time & 12,01 & 40 & 43,84 & 146 & 14,71 & 49 & 9,91 & 33 & 15,32 & 51 & 4,20 & 14 & 100 & 333 \\
\hline Waiting time of tests & 15,51 & 35 & 48,95 & 163 & 28,23 & 94 & 4,80 & 16 & 3,90 & 13 & 3,6 & 12 & 100 & 333 \\
\hline Results issuing time & 19,82 & 66 & 36,94 & 123 & 32,43 & 108 & 0 & 0 & 2,1 & 7 & 8,71 & 29 & 100 & 333 \\
\hline
\end{tabular}

\subsection{Conducting Clinical and Laboratory Tests}

From Table 4 it shows that during the course of clinical and laboratory tests, patients were satisfied with the staff behavior and with their respect for patient's personality in percentage of $60.96 \%-43.24 \%$.

Tabel 4. Conducting clinical and laboratory tests.

\begin{tabular}{|c|c|c|c|c|c|c|c|c|c|c|c|c|c|c|}
\hline \multirow[t]{2}{*}{$\begin{array}{l}\text { CONDUCTING CLINICAL AND } \\
\text { LABORATORY TESTS }\end{array}$} & \multicolumn{2}{|c|}{ Very good } & \multicolumn{2}{|c|}{ Rather good } & \multicolumn{2}{|c|}{$\begin{array}{l}\text { Neither good } \\
\text { nor bad }\end{array}$} & \multicolumn{2}{|c|}{$\begin{array}{l}\text { Rather } \\
\text { bad }\end{array}$} & \multicolumn{2}{|c|}{ Very bad } & \multicolumn{2}{|c|}{$\begin{array}{l}\text { Did not } \\
\text { answer }\end{array}$} & \multicolumn{2}{|c|}{ Total } \\
\hline & $\%$ & $\mathbf{N}$ & $\%$ & $\mathbf{N}$ & $\%$ & $\mathbf{N}$ & $\%$ & $\mathbf{N}$ & $\%$ & $\mathbf{N}$ & $\%$ & $\mathbf{N}$ & $\%$ & $\mathbf{N}$ \\
\hline Staff behavior & 60,96 & 203 & 19,82 & 66 & 5,11 & 17 & 0,3 & 1 & 9,31 & 31 & 4,5 & 15 & 100 & 333 \\
\hline Respect for the patient's personality & 43,24 & 144 & 16,22 & 54 & 23,72 & 79 & 0,6 & 2 & 9,31 & 31 & 6,91 & 23 & 100 & 333 \\
\hline
\end{tabular}

\subsection{Satisfaction from the Medical Care}

As reflected in Table 5, by majority the interviewees evaluated as very good and about at the same percentage the medical services regarding (a) the quality of medical care (experience, capability), (b) behavior (courtesy, friendliness, respect), (c ) complete and comprehensible information concerning the course of the disease treatment, (d) behavior during medical examinations and to a smaller percentage the services of psychological support.

Table 5. Satisfaction from the quality of medical services

\begin{tabular}{|c|c|c|c|c|c|c|c|c|c|c|c|c|c|c|}
\hline \multirow[t]{2}{*}{$\begin{array}{l}\text { IMPRESSIONS OF MEDICAL } \\
\text { CARE }\end{array}$} & \multicolumn{2}{|c|}{ Very good } & \multicolumn{2}{|c|}{ Rather good } & \multicolumn{2}{|c|}{$\begin{array}{l}\begin{array}{l}\text { Neither good } \\
\text { nor bad }\end{array} \\
\end{array}$} & \multicolumn{2}{|c|}{ Rather bad } & \multicolumn{2}{|c|}{ Very bad } & \multicolumn{2}{|c|}{$\begin{array}{l}\text { Did not } \\
\text { answer }\end{array}$} & \multicolumn{2}{|c|}{ Total } \\
\hline & $\%$ & $\mathbf{N}$ & $\%$ & $\mathbf{N}$ & $\%$ & $\mathbf{N}$ & $\%$ & $\mathbf{N}$ & $\%$ & $\mathbf{N}$ & $\%$ & $\mathbf{N}$ & $\%$ & $\mathbf{N}$ \\
\hline Medical care quality & 70,87 & 236 & 18,32 & 61 & 4,20 & 14 & 0 & 0 & 0,9 & 3 & 5,71 & 19 & 100 & 333 \\
\hline Doctors behavior & 72,37 & 241 & 15,92 & 53 & 4,2 & 14 & 0,0 & 0 & 0,9 & 3 & 6,61 & 22 & 100 & 333 \\
\hline Psychological support from doctors & 64,26 & 214 & 18,92 & 63 & 5,71 & 19 & 1,5 & 5 & 0,9 & 3 & 8,71 & 29 & 100 & 333 \\
\hline Full and comprehensible information & 68,47 & 228 & 16,52 & 55 & 5,71 & 19 & 0,6 & 2 & 1,8 & 6 & 6,91 & 23 & 100 & 333 \\
\hline Medical staff behavior & 70,27 & 234 & 18,32 & 61 & 2,40 & 8 & 0,0 & 0 & 0,9 & 3 & 8,11 & 27 & 100 & 333 \\
\hline
\end{tabular}

\subsection{Impressions of Nursing Care}

For the parameters that medical services were evaluated the nursing services were evaluated as very good, with a little deviation, at a lower rate $(67.57 \%-69.67 \%)$. (Table 6$)$ 
Table 6. Satisfaction from nurse care.

\begin{tabular}{|c|c|c|c|c|c|c|c|c|c|c|c|c|c|c|}
\hline \multirow[t]{2}{*}{$\begin{array}{l}\text { IMPRESSIONS OF NURSING } \\
\text { CARE }\end{array}$} & \multicolumn{2}{|c|}{ Very good } & \multicolumn{2}{|c|}{ Rather good } & \multicolumn{2}{|c|}{$\begin{array}{l}\text { Neither good nor } \\
\text { bad }\end{array}$} & \multicolumn{2}{|c|}{$\begin{array}{l}\text { Rather } \\
\text { bad }\end{array}$} & \multicolumn{2}{|c|}{ Very bad } & \multicolumn{2}{|l|}{$\begin{array}{l}\text { Did not } \\
\text { answer }\end{array}$} & \multicolumn{2}{|c|}{ Total } \\
\hline & $\%$ & $\mathbf{N}$ & $\%$ & $\mathbf{N}$ & $\%$ & $\mathbf{N}$ & $\%$ & $\mathbf{N}$ & $\%$ & $\mathbf{N}$ & $\%$ & $\mathbf{N}$ & $\%$ & $\mathbf{N}$ \\
\hline Healthcare quality & 69,67 & 232 & 12,61 & 42 & 2,7 & 9 & 0,0 & 0 & 0,9 & 3 & 14,11 & 47 & 100 & 333 \\
\hline Behavior & 69,67 & 232 & 16,22 & 54 & 0,9 & 3 & 0,0 & 0 & 0,9 & 3 & 12,31 & 41 & 100 & 333 \\
\hline Psychological support & 67,57 & 225 & 12,61 & 14 & 4,2 & 14 & 0,6 & 2 & 0,9 & 3 & 14.11 & 47 & 100 & 333 \\
\hline
\end{tabular}

\subsection{Administrative Services}

Interviewees evaluated from very good to rather good the administrative services related to (a) behavior (information, courtesy, friendliness, respect) in percentage $56.16 \%$ and $22.82 \%$ respectively, and (b) the throughput processes (service speed), in percentage $26.43 \%$ and $50.167 \%$, respectively (Table 7 ). It is obvious that patients reported lower satisfaction from administrative services, compared with medical and nursing care.

Table 7. Satisfaction from administrative services.

\begin{tabular}{|c|c|c|c|c|c|c|c|c|c|c|c|c|c|c|}
\hline \multirow[t]{2}{*}{$\begin{array}{l}\text { ADMINISTRATIVE } \\
\text { SERVICES } \\
\end{array}$} & \multicolumn{2}{|c|}{ Very good } & \multicolumn{2}{|c|}{ Rather good } & \multicolumn{2}{|c|}{$\begin{array}{l}\text { Neither good } \\
\text { nor bad }\end{array}$} & \multicolumn{2}{|c|}{ Rather bad } & \multicolumn{2}{|c|}{ Very bad } & \multicolumn{2}{|c|}{$\begin{array}{l}\text { Did not } \\
\text { answer }\end{array}$} & \multicolumn{2}{|c|}{ Total } \\
\hline & $\%$ & $\mathbf{N}$ & $\%$ & $\mathbf{N}$ & $\%$ & $\mathbf{N}$ & $\%$ & $\mathbf{N}$ & $\%$ & $\mathbf{N}$ & $\%$ & $\mathbf{N}$ & $\%$ & $\mathbf{N}$ \\
\hline Administrative staff behavior & 56,16 & 187 & 22,82 & 76 & 5,11 & 17 & 1,5 & 5 & 0,9 & 3 & 13,51 & 45 & 100 & 333 \\
\hline Throughput procedures & 26,43 & 88 & 50,167 & 167 & 11,41 & 38 & 1,2 & 4 & 1,8 & 6 & 9,01 & 30 & 100 & 333 \\
\hline
\end{tabular}

\subsection{General Service}

The $50.45 \%$ of the sample believes that the personal data was fully protected, while $35 \%$ belives that probably yes.

Table 8. General service.

\begin{tabular}{|c|c|c|c|c|c|c|c|c|c|c|c|c|c|c|}
\hline \multirow[t]{2}{*}{ GENERAL SERVICE } & \multicolumn{2}{|c|}{ Very good } & \multicolumn{2}{|c|}{ Rather good } & \multicolumn{2}{|c|}{$\begin{array}{l}\text { Neither good } \\
\text { nor bad }\end{array}$} & \multicolumn{2}{|c|}{$\begin{array}{l}\text { Rather } \\
\text { bad }\end{array}$} & \multicolumn{2}{|c|}{$\begin{array}{l}\text { Very } \\
\text { bad }\end{array}$} & \multicolumn{2}{|c|}{$\begin{array}{l}\text { Did not } \\
\text { answer }\end{array}$} & \multirow{2}{*}{\multicolumn{2}{|c|}{ Total }} \\
\hline & $\%$ & $\mathbf{N}$ & $\%$ & $\mathbf{N}$ & $\%$ & $\mathbf{N}$ & $\%$ & $\mathbf{N}$ & $\%$ & $\mathbf{N}$ & $\%$ & $\mathbf{N}$ & & \\
\hline Way of dealing with visitors or attendants & 44,44 & 148 & 37,84 & 126 & 8,11 & 27 & 0,3 & 1 & 0,0 & 0 & 9,31 & 31 & 100 & 333 \\
\hline Confidentiality (privacy) & 50,45 & 168 & 35,44 & 118 & 4,2 & 14 & 0,3 & 1 & 0,9 & 3 & 8,71 & 29 & 100 & 333 \\
\hline
\end{tabular}

To the question: "Would you choose to come back to our hospital?" 59\% (197) answered definitely yes and rather yes $37.24 \%$ (124). The majority of interviewees to the question "Would you recommend our hospital to friends and family?", $58 \% 86$ (196) answerd with definitely yes with and rather yes $36.94 \%$ (123)

\subsection{Overall Assessment of the Services}

In assessing the overall satisfaction is found that the ten-point scale ( 1 being the lowest price, 10 the value excellent), the Hospital is evaluated positively, the satisfaction rate amounts to $96.70 \%$ (values $7-10$ ). The average overall assessment score (8.3) is quite high (Figure 1).

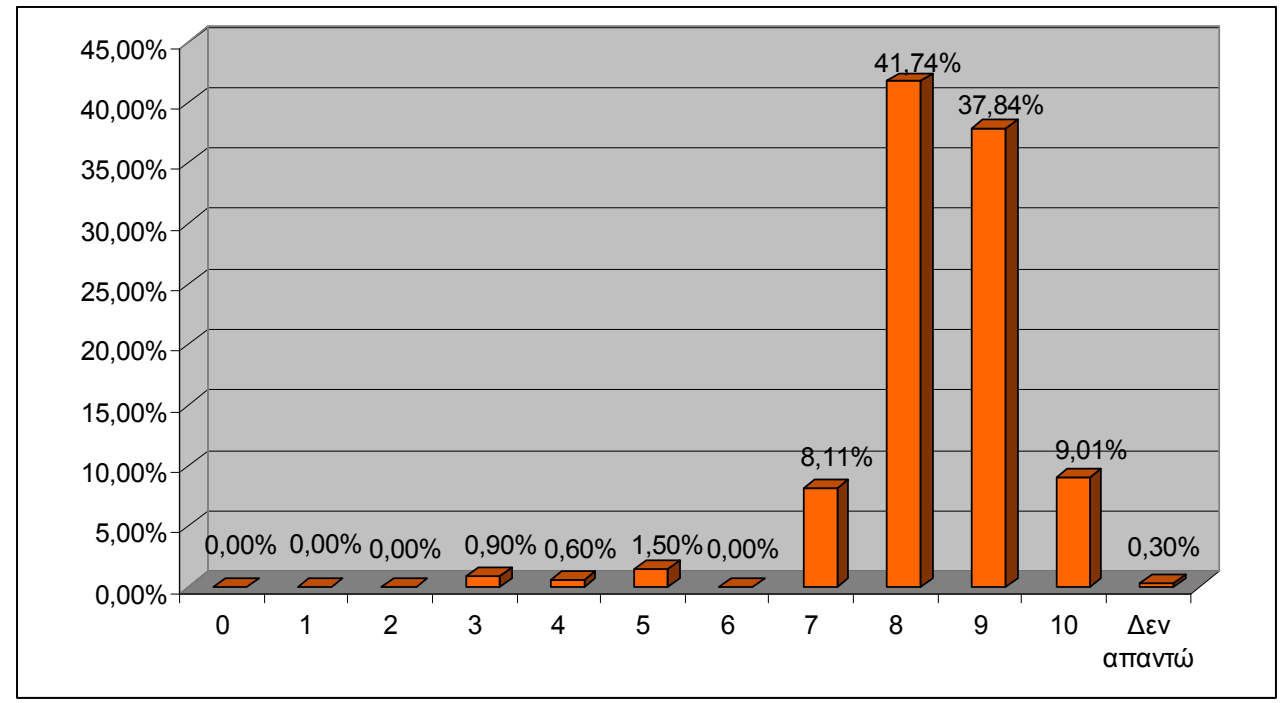

Figure 1. Overall assessment of services on the scale 1-10 (1 represents the lowest score and 10 the value excellent). 


\subsection{Overall Satisfaction Based on Patient Characteristics}

Based on the data given in Table 9, it appears that no clear correlation between the age of the studied population and the degree of satisfaction from the provided healthcare services. There is also no correlation between gender and overall satisfaction degree. After the statistical control ANOVA it shows that there is no statistically significant relationship between the education level and overall hospital evaluation ( $p$ $=>0,05$ ). The overall assessment of the hospital is not affected by the educational level of users of outpatient clinic health services that participated in the survey.

Table 9. Correlation between overall satisfaction and demographic characteristics.

\begin{tabular}{lcl}
\hline Variable & Average(SD) & p value \\
\hline Gender & & \\
Man & $8,41(0,927)$ & \\
Woman & $8,34(1,164)$ & 0,53 \\
Age & & \\
$>45$ Yers & $8,37(1,060)$ & \\
$<45$ Yers & $8,32(1,087)$ & 0,61 \\
\hline
\end{tabular}

\subsection{Limitations}

The main limitation of the study was that there was no possibility to explain the questions to respondents. Moreover, the results are not generalizable, as derived from the study of a single hospital.

\section{Discussion}

This research intended to measure patient satisfaction with the services provided by outpatient clinincs of a big General Hospital.

Summarizing the results of the research, was found that overall satisfaction with the services of outpatient clinincs is high, with an average total score (8.3). Analogs are the results of a survey done during the same period in other 8 different hospitals in Attica where for the same ten-point scale the average was 8.1. In a previous research in the same hospitals, the overall satisfaction of patients from outpatient clininc departments was lower on average 6.81 [21], [22].

Specific components recorded high levels of satisfaction and mainly the professionalism and availability of staff mainly for medical and nursing care. These results agree with the corresponding research findings, where the quality of the relationship between patient -staff -especially doctors- is estimated as one of the most important factors that influence the degree of user satisfaction [23], [24].

Additionally, the doctor- patient relationship is founded on mutual health maximization target [21], so when individuals take on the role of the patient they feel bad about criticizing the or may not believe that their role is to evaluate their doctor [18].

Besides these, patients more often don't have the knowledge or the necessary information (uneven information) to criticize the medical work. Perhaps this is why the ability, willingness, courtesy and the psychological support of nursing staff to patients is evaluated positively, without of course a big difference, however at lower percentage than the provision of medical care.

Regarding the administrative staff, patients appreciate the kindness of the reception staff and the time of task completion, while as the most important problem shows to be the long waiting time for making of appointment and the long wait before the test, compared to the appointment time. Low satisfaction rates recorded the waiting time for performing the tests and their results releasing time. Dissatisfaction for the long waiting time is reflected in research on patient satisfaction in outpatient clinics of Cyprus hospitals, and in researches done in other Greek hospitals [25]. In the research of Kabadai and Niakasit is shown that bureaucratic procedures and problems in the organization have a significant impact in the lower rating of administration [26].

The complexity of procedures and the deficiencies in coordination, influence the opinion of patients about the health system, as hospitals (secondary and tertiary) are invited to fill the gap in primary health care, thus burdening their functioning which in many cases is beyond their endurance limits, leading so to patients discomfort (e.g. waiting lists) and to operating costs increase. The implementation of quality management system plays an important role in patient satisfaction from the provided health servicesí [21]. Furthermore, any delay in the waiting time until the appointment may mean a delay in diagnosis and in the treatment of any patient problems with possible serious health consequences [18], [20].

Low levels of satisfaction recorded the questions on the ambient conditions, such as cleanliness, space temperature (heating - cooling), functional open spaces (seating, silence etc.). Dissatisfaction was expressed about the lack of information signs and the lack of infrastructure for the accessibility of people with disabilities. Similar conclusions are confirmed by the research of Niakas and Gnardelis, which showed that patient satisfaction is high for the medical and nursing services, but lower for the accommodations. This means that users of health services appear satisfied regarding to the behavior and the work of health professionals but recognize problems with the accommodation facilities and the level of service that support the operation of the hospital [27].

To a degree, the dissatisfaction can be attributed to the fact that during the period of the conducted research the Hospital was in progress of renovation maintenance work for building new wing (new surgeries). However, it is obvious that there is little space between the buildings compared to other hospitals in Attica and perhaps this makes it difficult to access.

Most studies in the literature are examining the relationship between demographic factors (age, gender and education level) and patient satisfaction. In this study there is no clear correlation between the age of the studied population and the degree of satisfaction from healthcare services provided. Furthermore, the overall assessment of the hospital is not influenced by gender and by education level of users of the 
outpatient clinics that participated to this research.

In a research study in hospitals of Cyprus, made during the same period, showed a significant positive correlation between age and satisfaction. Instead, as in this research, the results did not show any significant differences in satisfaction levels regarding gender and education level [25]. Other research on a national level in Taiwanese hospitals, found that patient characteristics, such as age, gender and level of education, influenced patient satisfaction to a small percentage [28]. National research on 63 hospitals of five Norwegian health regions (2006), showed that age, gender, and education level were not significant predictors of overall satisfaction of patients [29]. While two other studies reported that their results were strong influenced by two variables (age and gender) in score for overall patient satisfaction [30], [31].

The demographic factors are not modifiable and practically don't serve the managers of healthcare that want to improve patient satisfaction, although these characteristics should be taken into consideration when planning the patient satisfaction research in order to be used in comparative assessment with other healthcare institutions [32], [33].

The majority of interviewees of our study, would recommend the hospital to friends and family environment. The research of Papagiannopoulou and co. showed that users of health services are satisfied with the services, position supported by the fact that when interviewees are asked to answer the question if they would recommend the hospital to some of their own people with similar health problems, the overwhelming majority responded positively [34].

The result of review of research study about satisfaction of patients who have been hospitalized or patients who visit the outpatient clinicsof tertiary care hospitals, showed that there is a few information feedback about the improvements resulting by patient satisfaction surveys [7].

Based on the recommendations of the interviewees, as recorded in satisfaction questionnaires, the Hospital made the following improvement actions:

a Improvement of the system, the definition and management of medical appointments, in particular: a. Create an application for the secretariat of the outpatient clinics, which takes into account the cancellations and the modifications of appointments, providing relevant information to patients and physicians, b. Electronic notification of doctor about the daily list of patients, in order to avoid misunderstandings between patients on the order of priority for examination.

b Training of selected staff of outpatients clinics in communication and collaboration skills (listening and response techniques) to improve communication with the patient.

c Improvement of reception and waiting areas (direction signs, signs in each clinic, sufficiency of comfortable seats, modernization of W. C. facilities).

d A sufficient staffing of outpatient clinics and modernization of the necessary medical equipment.

\section{Conclusions}

In conclusion, the findings of the research confirmed the existence of similar problems to those identified in the majority of satisfaction surveys on Outpatient Clinic services of Greek NHS [23, 24, 29, 30]. The users are generally satisfied with the behavior and the work of health professionals, while they react more to organizational inefficiencies, delays and issues of Hospitals infrastructure. These problems should not be fragmentary dealt with, but in a strategy with defined objectives and priorities, by planning actions, monitoring and control of the course.

\section{References}

[1] Behm A., Bennington L., Cummane J. (2000) A value-creating model for effective policy services, Journal of Management Development, 19 (3): 162-178.

[2] Merkouris A., Papathanasoglou E., Lemonidou C. (2003) Evaluation of patient satisfaction with nursing care. Quantitative or Qualitative approach? International Journal of Nursing Studies, 41 (4), 355-67.

[3] Smith P. C., York N. (2004) Quality incentives: the case of U. K. general practitioners, HealthAffairs (Millwood), 23 (3): $112-118$.

[4] Sarris M. (2001) Sociology of health and quality of life, Papazisis, Athens, 450.

[5] Merkouris A. (1996) The satisfaction of the patient. Criterion quality nursing services. Doctoral Thesis. University of Athens. School of Health Sciences. Nursing Department. Athens.

[6] Prakash B. (2010) Patient satisfaction. J. Cutan Aesthet. Surg., 3 (3): 151-155.

[7] Al-Abri R., Al-Balushi A. (2014) Patient satisfaction survey as a tool towards quality improvement. Review Article. Oman Med. J., 29 (1): 3-7.

[8] Bleich S. N., Ozaltin E., Murray C. K. (2009) How does satisfaction with the health-care system relate to patient experience? Bulletin of the World Health Organization (WHO), 87: 271-278.

[9] Smith C. (1992) Validation of a patient satisfaction system in the United Kingdom. Qual. Assur. Health Care, 4 (3): 171-177.

[10] Donabedian A. (1988) Quality assessment and assurance: Unity of purpose, diversity of means. Inquiry 25 (1): 173-192.

[11] Donabedian A. (1988) The quality of care. How it can be assessed? JAMA, 260 (12): 1743-1748.

[12] Avis M., Bond M., Arthur A. (1995) Satisfying solutions? A review of some unresolved issues in the measurement of patient satisfaction. J. Adv. Nurs., 22(2): 316-322.

[13] Guzman P. M., Sliepcevich E. M., Lacey E. P., VitelloE. M., Matten M. R., WoehlkeP. L. et al. (1988) Tapping patient satisfaction: A strategy for quality assessment. Patient Educ. Couns., 12(3):225-233.

[14] Petersen M. B. (1988) Measuring patient satisfaction: Collecting useful data. J. Nurs. Qual. Assur. 1988, 2 (3): 25-35. 
[15] Tsaousoglou A., Koukourikos K. (2007) Quality and health services Stigma, 15 (2): 18-24.

[16] Pierrakos C. (2008) Primary health care and local community Papazisis, Athens, 99.

[17] Papanikolaou V. (1994) Satisfying healthcare users in Greece. Doctoral thesis. Department of Psychology. Panteion University of Social and Political Sciences. Athens.

[18] Carr-Hill R. A. (1992) The measurement of patient satisfaction. J. Public Health Med., 14 (3): 236-249.

[19] Zoller J. S., Lackland D. T., Silverstein M. D. (2001) Predicting patient intent to return from satisfaction scores. J. Ambul. CareManage, 24 (1): 44-50.

[20] Aletras V., Zacharaki F.,. Niakas D. (2007) Questionnaire for the measurement of outpatient satisfaction in the ophthalmology clinic of a Greek public hospital. Archives of Hellenic Medicine, 24 (1): 89-96.

[21] Pierrakos G., Sarris M., Soulis S., Goula A., Latsou D., Pateras I., Vourliotou K., Giannoulatos P. (2013) Comparative analysis of two studies of outpatient satisfaction in primary medical care. Archives of Hellenic Medicine, 30 (3): 316-324.

[22] Hiidenhovi H., Nojonen K., Laippala P. (2002) Measurement of outpatients' views of service quality in a Finnish university hospital. J Adv. Nurs., 38 (1): 59-67.

[23] Bergenmar M., Nylen U., Lidbrink E., Brandberg Y. (2006) Improvements in satisfaction at an outpatient clinic for patients with breast cancer. ActaOncol, 45 (5): 550-558.

[24] Ekwall A., Gerdtz M., Manias E. (2008) The influence of patient acuity on satisfaction with emergency care: Perspectives of family, friends and carers. J. Clin. Nurs., 17 (6): 800-809.

[25] Gabriel E., Theodorou M., Middleton N.(2012) Patient satisfaction from the services provided by the outpatient clinics in the public hospitals of Cyprus. Archives of Hellenic Medicine, 29 (6): 720-730.
[26] Kabadai M., Niakas D. (2004) Patient satisfaction with services provided by a Community Mental Health Center in northern Greece. Archives of Hellenic Medicine, 21 (4): 354-362.

[27] Niakas D., Gnardelis Ch. (2000) Satisfaction inpatient in a regional general hospital in Athens. Medicine, 77 (5): 464-470.

[28] Shou-Hisa C., Ming-Chin Y., Tung-Uang C. (2003) Patient satisfaction with and recommendation of a hospital: effects of interpersonal and technical aspects of hospital care. International Journal for Quality in Health Care, 15 (4): 345-355.

[29] Bjertnaes O. A., Sjetne I. S., Iversen H. H. (2012) Overall patient satisfaction with hospitals: effects of patient-reported experiences and fulfillment of expectations. British Medical Journal Quality Safety, 21 (1): 39- 46.

[30] Tonio S., Joerg K., Joachim K. (2011) Determinants of patient satisfaction: a study among 39 hospitals in an in-patient setting in Germany. International Journal for Quality in Health Care, 23 (5): 503-509.

[31] Rama M., Kanagaluru S. K. (2011) A study on the satisfaction of patients with reference to hospital services. International Journal of Business Economics \& Management Research, 1 (3): $15-25$.

[32] Koichiro O., Brian W., Kelly M. F., Sarah B., Thomas E. B., Claiborne D. (2009), Patient Satisfaction: Focusing on "Excellent", Journal of Healthcare Management, 54 (2): 93-103.

[33] Quintana J. M., Gonzalez N., Bilbao A., Aizpuru F., Escobar A., Esteban C., San- Sebastian J. A., De la Sierra E., Thompson A. (2006) Predictors of patient satisfaction with hospital health care. BMC Health Services Research, 6:102, pp.1-9. http://www.biomedcentral.com/1472-6963/6/102.

[34] Papagiannopoulou V., Pierrakos G., Sarris M. (2008) Yfantopoulos J. Measuring satisfaction with health care services in an Athens pediatric hospital. Archives of Hellenic Medicine, 25 (1): 73-81. 